\title{
Flavonoids and Their Biological Secrets
}

\author{
M. I. Rashid, M. I. Fareed, H. Rashid, H. Aziz, N. Ehsan, S. Khalid, \\ I. Ghaffar, R. Ali, A. Gul, and Khalid Rehman Hakeem
}

\section{Introduction}

\section{Flavonols}

3-Hydroxy flavones or flavonols, one major subclass of flavonoids, are polyaromatic secondary plant metabolites. Their structure consists of general three-ring backbone of flavonoids, i.e., rings A, B, and C. Flavones are classified as flavanones when there is a hydroxyl group attached to the 3-position of $\mathrm{C}$ ring. Structures of flavonol and flavone molecules are shown in the figure.

In higher plants, flavonols are present in glycosylated form; most abundant are the $O$-glycosides. The sugar residues commonly found in flavonols are glucose, galactose, rhamnose, and glucuronic acid. Glycosylation is reported at 3-, 7-, 3-, and $4^{\prime}$-positions (Table 1).

Flavonols are present in various parts of plants including leaves, fruits, and vegetables. Among different plants tested for flavonols, their highest concentration was found in strawberry (Fragaria spp.), peepal (Ficus religiosa), spinach (Spinacia oleracea), and cauliflower (Brassica oleracea) (Sultana and Anwar 2008). Like

\footnotetext{
M. I. Rashid · M. I. Fareed · H. Rashid · H. Aziz · N. Ehsan · S. Khalid · A. Gul ( $₫)$ Atta-ur-Rahman School of Applied Biosciences (ASAB), National University of Sciences and Technology (NUST), Islamabad, Pakistan e-mail: alvina_gul@asab.nust.edu.pk

I. Ghaffar

University College of Pharmacy (UCP), University of the Punjab, Lahore, Pakistan

R. Ali

Institute of Basic Medical Sciences, Khyber Medical University, Peshawar, Pakistan

K. R. Hakeem

Department of Biological Sciences, Faculty of Science, King Abdulaziz University, Jeddah, Saudi Arabia
} 
Table 1 The relative substitutions among the 15 different flavonoids discussed in the paper

\begin{tabular}{|c|c|c|c|c|c|c|c|c|c|c|}
\hline \multirow[b]{2}{*}{ Sr.\# } & \multirow[b]{2}{*}{ Flavonols } & \multicolumn{9}{|c|}{ Position } \\
\hline & & $2^{\prime}$ & $3^{\prime}$ & $4^{\prime}$ & $5^{\prime}$ & 3 & 5 & 6 & 7 & 8 \\
\hline 1 & 3-Hydroxyflavone & $\mathrm{H}$ & $\mathrm{H}$ & $\mathrm{H}$ & $\mathrm{OH}$ & $\mathrm{H}$ & $\mathrm{H}$ & $\mathrm{H}$ & $\mathrm{H}$ & $\mathrm{H}$ \\
\hline 2 & Azaleatin & $\mathrm{H}$ & $\mathrm{OH}$ & $\mathrm{OH}$ & $\mathrm{H}$ & $\mathrm{OH}$ & $\mathrm{OCH}_{3}$ & $\mathrm{H}$ & $\mathrm{OH}$ & $\mathrm{H}$ \\
\hline 3 & Fisetin & $\mathrm{H}$ & $\mathrm{H}$ & $\mathrm{OH}$ & $\mathrm{OH}$ & $\mathrm{OH}$ & $\mathrm{H}$ & $\mathrm{H}$ & $\mathrm{OH}$ & $\mathrm{H}$ \\
\hline 4 & Galangin & $\mathrm{H}$ & $\mathrm{H}$ & $\mathrm{H}$ & $\mathrm{H}$ & $\mathrm{OH}$ & $\mathrm{OH}$ & $\mathrm{H}$ & $\mathrm{OH}$ & $\mathrm{H}$ \\
\hline 5 & Gossypetin & $\mathrm{H}$ & $\mathrm{OH}$ & $\mathrm{OH}$ & $\mathrm{H}$ & $\mathrm{OH}$ & $\mathrm{OH}$ & $\mathrm{H}$ & $\mathrm{OH}$ & $\mathrm{OH}$ \\
\hline 6 & Isorhamnetin & $\mathrm{H}$ & $\mathrm{OCH}_{3}$ & $\mathrm{OH}$ & $\mathrm{H}$ & $\mathrm{OH}$ & $\mathrm{OH}$ & $\mathrm{H}$ & $\mathrm{OH}$ & $\mathrm{H}$ \\
\hline 7 & Kaempferide & $\mathrm{H}$ & $\mathrm{H}$ & $\mathrm{OCH}_{3}$ & $\mathrm{H}$ & $\mathrm{OH}$ & $\mathrm{OH}$ & $\mathrm{H}$ & $\mathrm{OH}$ & $\mathrm{H}$ \\
\hline 8 & Kaempferol & $\mathrm{H}$ & $\mathrm{H}$ & $\mathrm{OH}$ & $\mathrm{H}$ & $\mathrm{OH}$ & $\mathrm{OH}$ & $\mathrm{H}$ & $\mathrm{OH}$ & $\mathrm{H}$ \\
\hline 9 & Morin & $\mathrm{OH}$ & $\mathrm{H}$ & $\mathrm{OH}$ & $\mathrm{H}$ & $\mathrm{OH}$ & $\mathrm{OH}$ & $\mathrm{H}$ & $\mathrm{OH}$ & $\mathrm{H}$ \\
\hline 10 & Myricetin & $\mathrm{H}$ & $\mathrm{OH}$ & $\mathrm{OH}$ & $\mathrm{OH}$ & $\mathrm{OH}$ & $\mathrm{OH}$ & $\mathrm{H}$ & $\mathrm{OH}$ & $\mathrm{H}$ \\
\hline 11 & Natsudaidain & $\mathrm{H}$ & $\mathrm{H}$ & $\mathrm{OCH}_{3}$ & $\mathrm{OCH}_{3}$ & $\mathrm{OH}$ & $\mathrm{OCH}_{3}$ & $\mathrm{OCH}_{3}$ & $\mathrm{OCH}_{3}$ & $\mathrm{OCH}_{3}$ \\
\hline 12 & Pachypodol & $\mathrm{H}$ & $\mathrm{H}$ & $\mathrm{OH}$ & $\mathrm{OCH}_{3}$ & $\mathrm{OCH}_{3}$ & $\mathrm{OH}$ & $\mathrm{H}$ & $\mathrm{OCH}_{3}$ & $\mathrm{H}$ \\
\hline 13 & Quercetin & $\mathrm{H}$ & $\mathrm{OH}$ & $\mathrm{OH}$ & $\mathrm{H}$ & $\mathrm{OH}$ & $\mathrm{OH}$ & $\mathrm{H}$ & $\mathrm{OH}$ & $\mathrm{H}$ \\
\hline 14 & Rhamnazin & $\mathrm{H}$ & $\mathrm{OCH}_{3}$ & $\mathrm{OH}$ & $\mathrm{H}$ & $\mathrm{OH}$ & $\mathrm{OH}$ & $\mathrm{H}$ & $\mathrm{OCH}_{3}$ & $\mathrm{H}$ \\
\hline 15 & Rhamnetin & $\mathrm{H}$ & $\mathrm{OH}$ & $\mathrm{OH}$ & $\mathrm{H}$ & $\mathrm{OH}$ & $\mathrm{OH}$ & $\mathrm{H}$ & $\mathrm{OCH}_{3}$ & $\mathrm{H}$ \\
\hline
\end{tabular}

other flavonoids, flavonols are most apparent antioxidant in higher plants. Antioxidative activity of flavonols has been shown experimentally to prevent nuclear DNA damage by hydrogen peroxide in plants (Melidou et al. 2005). Studies on Arabidopsis plant have shown that flavonols are involved in providing protection to plant leaves against oxidative damage due to excessive visible radiation (Havaux and Kloppstech 2001). They are also involved in providing defense against fungal infection to plant leaves (Treutter 2006).

Despite their role in plant survival, biological activities of flavonols also contribute to human health. Antiviral activities of flavonoids were discovered in the first half of the twentieth century. Hydroxyl group at 3-position makes flavonols more effective against herpes simplex virus type 1 than flavones (Cody et al. 1986; Selway 1986). Anti-inflammatory response of flavonol has also been reported on animal models for both chronic and acute inflammation (Lee et al. 1993). Flavonols also involved in antithrombogenic effect by preventing platelet aggregation (Gryglewski et al. 1987).

\section{Fisetin}

Fisetin is a special class of flavonoid compounds defined as 3,3', $4^{\prime}, 7$-tetrahydroxyflavone, 6-desoxyquercetin, and fisidenolon; its empirical formula is $\mathrm{C}_{15} \mathrm{H}_{10} \mathrm{O}_{6}$. In plants it is present as glycoside fisetin-8-glucoside. Chemically it is defined as -(3,4-dihydroxyphenyl)-3,7-dihydroxy-4H-1-benzopyran-one and $3,3^{\prime}, 4,7$-tetrahydroxy-2-phenylchromen-4-one. Fisetin usually is found in plants as the glycoside fisetin-8-glucoside. 
It is a basic 15-carbon structure also known as diphenylpropane molecule having two aromatic rings which is linked through three carbon atoms. Flavonoids make difference because of the saturation of the heteroatomic ring $\mathrm{C}$, in place of $\mathrm{B}$ at position C-2 or C-3 of ring $\mathrm{C}$ and throughout patterns of methoxylation (Nijveldt et al. 2001).

\section{Biological Properties}

Natural polyphenolic compounds including flavonoids are present in fruits, vegetables, and some beverages (Aherne and O'Brien 2002). They have role in pharmaceutics and have the potential of treating cancer and heart diseases (Havsteen 2002; Hill et al. 1989; Lopez-Lazaro 2002; Middleton et al. 2000; Monasterio et al. 2004). It has been discovered that few flavonoids have also a role in the organization of cytoskeleton especially in the assembly of tubulin.

According to the reported data, fisetin is the most active member of flavonoid compounds and shows a role in the modification of morphology of endothelial cells that is related to the stabilization of microtubule and to the $\alpha$-tubulin acetylation which is known to be a distinctive marker for the stabilization of tubulin. Such type of presented data has been useful for us in the selection of food which has such type of active flavonoids acting against cancer and other diseases.

Flavonoid compounds showed responses against inflammation, allergy, and bacterial infection (Melgarejo et al. 2007; Middleton et al. 2000; Williams and Grayer 2004). Fisetin is an important class of flavonoid compounds found in a variety of fruits and vegetables which is responsible for decreasing the process of degranulation of mast cells (Arai et al. 2000).

It has been discovered that fisetin has a role in the differentiation of nerve cells and also protects them from death due to oxidative stress (Ishige et al. 2001; Sagara et al. 2004). It has been studied that fisetin possesses also the properties of antiaging. Fisetin has also a role in rising the serotonin and non-adrenaline levels in the brain which results in the production of effect against depression (Zhen et al. 2012).

Fisetin also has a role in the promotion of growth and maintenance of nerve cells without the help of neurotropic factors. These are important factors because if those factors are removed, it will result in the death of nerve cells. In the absence of those factors, fisetin is invovled promotion of growth and survival of nerve cells (Maher 2006, 2008).

NF-kappa B pathway plays an important role in inflammation which results in the progression of cancer. Fisetin and some other flavonoids perform an important role in the suppression of numerous inflammatory pathways most importantly NF-kappa B pathway which is important in many remedies against cancer (Gupta et al. 2010; Prasad et al. 2010; Sung et al. 2007).

Fisetin has also a role in the prevention of Huntington's disease which is an important neurodegenerative disorder affecting various brain functions (Maher et al. 2011a). Wnt signaling pathway has an important role in the proliferation and 
progression of cancer; fisetin compound performs function in inhibition of this pathway (Teiten et al. 2012).

It has been studied that fisetin performs function against pulmonary inflammation infection, against asthma specifically doing by downregulation of NF-kappa B pathway (Wu et al. 2011). Many other flavonoids including fisetin decrease the activation of mast cell which reduces the histamine level as a result of which inhibition of many allergies occurs. Because when mast cells become active, they tend to secrete histamine and many other pro-inflammatory compounds (Park et al. 2008).

Fisetin makes the high expression of glyoxalase 1 which is an important enzyme and plays a significant role in the exclusion of substances and reducing the levels of glycated proteins responsible for diabetes (Maher et al. 2011b). In contrast if the expression of glyoxalase 1 becomes low, it leads to the increased level of glycation and complications in diabetes (Miyata et al. 2001).

Also by decreasing the secretion of glucose from the liver, fisetin hinders the hyperglycemia which is induced due to the glucose secretion from the liver (Constantin et al. 2010).

\section{Galangin}

Galangin is an important class of flavonoid compounds; they are found in honey, propolis, Helichrysum aureonitens, and Alpinia officinarum in greater amount. This compound has an important role in pharmaceutics; also it performs function against oxidation, against mutations, and against cancer (Cushnie and Lamb 2006; Gwak et al. 2011; Heo et al. 2001).

It has three hydroxyl groups on its carbon ring, and it has the capability of enzyme modulation and can decrease the chemical toxicity (Chen et al. 2008). It has been reported earlier that galangin has a role in the inhibition of aryl hydrocarbon receptor; in organisms these compounds are also involved in certain biological activities at nontoxic levels (Murray et al. 2006).

\section{Biological Properties}

By using the agar dilution assay, it was studied that galangin also showed its activity against the 17 strains of Staphylococcus aureus species which was resistant against quinolone. In a specific strain when there is a change in the amino acid in the GrlB subunit of topoisomerase IV, it results in its increase receptiveness toward galangin. Therefore topoisomerase IV enzyme plays an important role in the function of galangin against bacterial infection (Cushnie 2006).

The activity of galangin was also discovered against 17 strains of Campylobacter jejuni and several gram-positive and gram-negative strains, but the highest galangin activity was found against the 17 strains of Campylobacter jejuni (Campana et al. 2009). 
In colorectal and liver cancer, the transcriptional process of beta-catenin is increased; galangin reduces its transcription by the elimination of beta-catenin inside the cell. This compound also decreases the levels of beta-catenin by making the mutations inactive of adenomatous polyposis coli (Gwak et al. 2011).

According to the in vivo and in vitro studies, it has been reported that galangin has the capability of performing functions in the regulation of enzyme activity and in decreasing the toxic effect of chemicals and against oxidation (Heo et al. 2001). Galangin has been found in liposomes; these liposomes have been analyzed for their activities against oxidation, and results have showed that liposomes which have greater concentration of galangin have more antioxidative activity (Landi-Librandi et al. 2011).

The effect of galangin was studied in rat liver which was fed on fructose; the high expression of plasma glucose, triglycerides, and insulin was prohibited by galangin; and furthermore it also increases the sensitivity of insulin, while galangin also plays an important role in decreasing the expression of cytokines. It also prohibited the high translocation of NF-kappa B (Sivakumar and Anuradha 2011).

HPLC and MS have been used in finding the quantification of galangin in biological samples, and results showed that these compounds are aggregated more in the nucleus than cytoplasm (Mukai et al. 2009). According to chromatographic studies, galangin is also available in propolis of Lactobacillus fermentum (Saavedra et al. 2011). It has been discovered after the analysis of seven different types of Slovenian honey that it contains the greater amount of galangin (Bertoncelj et al. 2011).

Extracts of different plants have galangin which is considered to be the most active compound (Yang et al. 2011b). Concentration of polyphenol in fruits and leaves of Ficus carica has shown the occurrence of galangin as a major constituent (El-Shobaki et al. 2010).

By using the technique of HPLC, seven different phenolic components were discovered in bee pollen sample, among which galangin was the most active and also galangin was found in different fruits which were taken from Italy (Grippi et al. 2007; Šrić et al. 2009). Galangin was also discovered from the 120 samples of Chinese propolis which were detected by using the fingerprint method (Chen et al. 2008).

Galangin was significantly found in the chemical composition of propolis which was taken from arid and semiarid areas of Sonora, Mexico, Europe, China, and Argentina (Gardana et al. 2007). Galangin was also found from the extracts of apple and parsley (Abdel-Rahim and El-Beltagi 2010).

\section{Gossypin}

Gossypin (3,3', $4^{\prime}, 5,7$-pentahydroxy-8-O-glucosylflavone) is a flavonol and a derivative of gossypetin. It is a monoglucoside. On complete methylation and hydrolysis, it gives an $O$-pentamethyl gossypetin (Rao and Seshadri 1946b). The presence of 
glucose moiety in the eighth position of hexahydroxyflavone makes it water soluble (Gautam and Vijayaraghavan 2007).

It was initially extracted from Gossypium indicum (Neelakantam and Seshadri 1936). However, the species Gossypium indicum did not yield sufficient amount of gossypin to carry out further experimentation. It was then found out that Hibiscus vitifolius was a rich source of gossypin (Rao and Seshadri 1946a). A detailed study of the structure and function of the flavonol has been carried out since.

\section{Biological Properties}

Major focus of today's research is finding a cure for cancer. To avoid the harms of chemotherapy and radiotherapy, scientists now look toward natural products with higher efficacy and fewer side effects. In this regard, the anticancer activity of gossypin has been investigated by many researchers. A study by Babu et al. (2003) demonstrated the anticarcinogenic activity of the bioflavonoid gossypin against the carcinogens such as DMBA which causes skin papillomas in mouse. Moreover it was shown to decrease the tumor burden in solid tumors and inhibition of angiogenesis. The antitumor activity of gossypin is attributed somewhat to its ability to inhibit the key enzymes in DNA replication, the topoisomerase I and II (Babu et al. 2003). In another study conducted on human glioma, U251 cells treated with gossypin showed promising results. Gossypin caused cell cycle arrest at G2/M phase involving the phosphorylation of cell division cycle 25C (Cdc25C) tyrosine phosphatase through the stimulation of checkpoint kinase 1 (Chk1) (Shi et al. 2012). Additionally gossypin has been found to block cell multiplication in L929, HT29, and K562 tumor cell lines in vitro (Babu et al. 2003). Another possible mechanism underlying anti-tumorigenic capability of gossypin was demonstrated by Kunnumakkara et al. (2007). They analyzed the effect of gossypin on NF-kappa B, a master regulator involved in inflammation, carcinogenesis, hyper-proliferation, invasion, and angiogenesis. The results supported the hypothesis of possible NF-kappa B inhibition by gossypin (Kunnumakkara et al. 2007).

Gossypin's role as a potent antioxidant was examined in a study involving lead toxicity. Lead is known to cause generation of reactive oxygen species (ROS) and destruction of antioxidant reserves in the body (Patrick 2006; Silbergeld et al. 2000). Gautam et al. demonstrated the significance of co-administrating gossypin during lead exposure. They concluded that gossypin prevents lead-induced oxidative stress by chelating lead, stimulating the enzymes involved in protecting antioxidant reserves, and by inducing delta-aminolevulinic acid dehydratase, which is primarily targeted by lead (Gautam and Flora 2010).

Not only gossypin is effective in its antitumor activities, but its potential role in alleviating many other pathologies is also under consideration. Many of the current orally administrated hypoglycemic drugs for the treatment of diabetes mellitus induce harmful side effects. A study was conducted to evaluate the antidiabetic effect of gossypin in streptozotocin (STZ)-induced experimental diabetes in rats. 
Results revealed a strong antidiabetic activity of gossypin against STZ-induced experimental diabetes (Venkatesan and Sorimuthu Pillai 2012).

Epilepsy is a set of neurological disorders characterized by recurrent or single seizures accompanied by alterations in the brain (Chang and Lowenstein 2003; Fisher et al. 2005). To avoid the drug interactions caused by the many antiepileptic drugs, researchers are investigating natural alternatives with fewer side effects. In this pursuit, gossypin was used in a set of experiments to evaluate its anticonvulsant activity. The results obtained emphasized the importance of gossypin against convulsions probably by influencing the GABA aminergic and glycine inhibitory mechanism (Rasilingam et al. 2008).

Mast cell degranulation and release of histamines and other inflammatory cytokines underlie severe allergic reactions. Gossypin was shown to inhibit anaphylaxis in a rat model of allergy (Ganapaty et al. 2010). The anti-inflammatory activity of gossypin is thought to be the consequence of inhibition of arachidonic acid breakdown through blocking of the cyclooxygenase and lipoxygenase enzymes (Ferrandiz and Alcaraz 1991). Gossypin also has a potent effect against sulfur mustard (SM), a blistering agent, possibly through its anti-inflammatory action (Gautam and Vijayaraghavan 2007).

Gossypin has also been shown to relieve pain in mice, acting as an analgesic possibly through the induction of opiate receptors (Viswanathan et al. 1984).

\section{Isorhamnetin}

Isorhamnetin ( $3^{\prime}$-methoxy-3,4',5,7-tetrahydroxyflavone) is an $O$-methylated flavonol occurring naturally in plants but is also a metabolic product of quercetin(isorhamnetin is methylated quercetin) (phytochemicals.info). It can be extracted from Tagetes lucida (Bohm and Stuessy 2001). It is mostly found in fruits and medicinal herbs (Kim et al. 2011). Isorhamnetin is a metabolite of quercetin, a widely distributed natural flavonol (Anderson 2004).

\section{Biological Properties}

Isorhamnetin has found its promising role in treatment of various diseases such as cardiovascular disorders, rheumatism, and hemorrhage (Gupta et al. 2010; Ma et al. 2007a; Suomela et al. 2006). Isorhamnetin is known to have cardiovascular effects. Isorhamnetin and its parent compound quercetin caused endothelium-independent vasodilatation in the aorta, mesenteric arteries, portal vein, and porcine coronary arteries of rat (Ibarra et al. 2002).

Anti-inflammatory activity of isorhamnetin was observed in murine RAW264.7. Analysis was performed based on the expression of pro-inflammatory markers in lipopolysaccharide-stimulated murine macrophages (Boesch-Saadatmandi et al. 
2011). The possible way by which isorhamnetin blocks inflammation is not yet clear; however the study by Boesch-Saadatmandi et al. suggested the inhibition of NF-kappa B to have a significant role in this regard (Boesch-Saadatmandi et al. 2011).

A derivative of isorhamnetin, isorhamnetin 3-O neohesperidoside (I3ON), has potential antioxidant activity and protective capability against DNA damage caused by hydroxyl free radical (Bouhlel et al. 2009).

Osteoporosis is mainly attributed to estrogen deficiency in postmenopausal women (Richelson et al. 1984). Different flavonols were examined for their estrogen receptor agonist activity. Isorhamnetin along with other flavonols under study exhibited stimulatory activity for estrogen receptors, thereby producing the required osteogenic effects (Yang et al. 2011a).

Isorhamnetin has been found useful in treating obesity as it has an anti-adipogenic action. Differentiation of human adipose tissue-derived stem cells into adipocytes is controlled in different ways. Wnt signaling, being one of the chief regulatory mechanisms in the differentiation process, is targeted by isorhamnetin mainly by the stabilization of $\beta$-catenin (Lee et al. 2010).

As for the role of isorhamnetin in cancer, it is shown to exert antitumor activity. One of the possible mechanisms for this anticancerous activity was delineated by Kim et al. (2011) in a study of skin cancer. In this study isorhamnetin blocked epidermal growth factor (EGF)-induced neoplastic cell transformation by suppressing the expression of COX-2 protein. COX-2 is a major inflammatory mediator and exerts pro-tumorigenic activity (Méric et al. 2006). Furthermore it exerted a negative effect on anchorage-dependent and anchorage-independent growth of A431 human epithelial carcinoma cell line (Kim et al. 2011). Many other evidences support isorhamnetin's role in reducing cell growth and weight and size of tumors (Ma et al. 2007a; Steffen et al. 2008). Another set of experiments revealed antitumor role of isorhamnetin by inhibition of the cell cycle protein, farnesyl protein transferase (FPTase) (Oh et al. 2005). Previously, quercetin was shown to be a potent anticancer agent, but newer studies have signified the increased potential of isorhamnetin an effective anticancer entity. Such isorhamnetin showed elevated levels of cytotoxicity against cancerous cells as compared to quercetin. It induces necrosis and apoptosis in human colon cancer cell line (HCT-116) (Jaramillo et al. 2010). Moreover in another research aflatoxin B1 (AFB1)-mediated oxidative stress was lessened considerably by isorhamnetin more than quercetin in hepatocellular carcinoma cells (Choi et al. 2010).

Isorhamnetin was shown to reduce proliferation and stimulate apoptosis in gastric cancer. These functions were mediated through the activation of peroxisome proliferator-activated receptors (PPAR- $\gamma$ ) which is known to be involved in promoting tumorigenesis in gastric cancer. The results by Ramachandran et al. provide a strong basis for establishment of combination therapy involving the use of isorhamnetin to reduce the side effects and enhance treatment efficacy for gastric cancer (Ramachandran et al. 2012). 


\section{Kaempferol/Kaempferide}

3,5,7-Trihydroxy-2-(4-hydroxyphenyl)-4H-1-benzopyran-4-one kaempferol is a class of flavonol compounds (Calderon-Montano et al. 2011). It is abundantly found in edible plants and one of the most important flavonoid compounds (Miean and Mohamed 2001a). These plants include tea (Park et al. 2006a), broccoli (CalderonMontano et al. 2011), cabbage (Calderon-Montano et al. 2011), and strawberries (Calderon-Montano et al. 2011; Hakkinen et al. 1999), and other dietary plants (Calderon-Montano et al. 2011). Previously during epidemiological research, it has been observed that these dietary plants also used for human health betterment and during various preclinical and clinical trials have revealed that kaempferol-rich diet overcomes the human malignancy development (Kim et al. 2003). Many naturally occurring glycosides of kaempferol are extracted from different plants. These glycosides are kaempferitrin (kaempferol 3,7-dirhamnoside) (Vishnu Prasad et al. 2009), astragalin (Wei et al. 2011), afzelin (kaempferol 3-rhamnoside) (Markham et al. 1992), kaempferol 7-O-glucoside (Ibrahim et al. 2008), robinin (kaempferol3-O-robinoside-7-O-rhamnoside) (March et al. 2004), sophoraflavonoloside (kaempferol 3-O-sophoroside) (Kim et al. 2012), and trifolin (kaempferol-3-Ogalactoside) (Nowak and Wolbis 2002). Kaempferol-3-O- $\beta$-D-glucopyranoside-7$O$ - $\alpha$-L-rhamnopyranoside is one of the most bitter-tasting glycoside compounds and has been isolated from the methanolic plants (Gohar et al. 2000; Ragasa et al. 2005). During the metabolism process by the activity of enzyme transferase, these flavonoid kaempferol compounds can transfer the product of kaempferol and $S$-adenosyl methionine to kaempferide (Calderon-Montano et al. 2011; Curir et al. 2001). Kaempferide is defined as $4^{\prime}-O$-methylkaempferol which is also included in chemical flavonoid compound (Curir et al. 2001). These isolated flavonoid and chemical compounds have an antimicrobial (Yang et al. 2010), antioxidant (Choi et al. 2013), anticancer (Calderon-Montano et al. 2011), neuroprotective (Filomeni et al. 2012), antidiabetic (Habtemariam 2011), immunomodulatory (Kim et al. 2008), antiosteoporotic, antiestrogenic (Oh et al. 2006), anxiolytic (Vissiennon et al. 2012), analgesic (Tsiklauri et al. 2011), and anti-allergic activities (Kim et al. 2008). Therefore naturally occurring plants are usually used as medicinal plants and for pharmaceutical products. The study of immunopharmacological properties of these plants has clearly shown the result to inhibit the cell growth, oxidative low-density lipoprotein (LDLP) suppression, viral inhibition, and reduction of apoptosis and strengthen the immune system (Kim et al. 2008). Kaempferol and kaempferide are developed by the metabolic activities of bioactive plants and are agents to treat many disorders (Kim et al. 2008). Ginkgo biloba, Moringa oleifera, Equisetum spp., Tilia spp., propolis, and Sophora japonica are the species of medicinal productivity (Calderon-Montano et al. 2011). For the cure of free radical damages and different infectious diseases, these pharmacokinetics species have often been utilized (Calderon-Montano et al. 2011). It was indicated that kaempferol compound in plants can be used as an agent of chemo-protection (Chen and Chen 2013). Recently it was observed that hypertension stress that associated with cardiac risks 
has been suppressed by the consumption of this anticancer compound in tea and broccoli(Calderon-Montano et al. 2011). It has been concluded that kaempferol also plays a vital role to overcome the inflammatory response (Choi et al. 2013). Kaempferol also suppresses the translational activity of particular protein that may help to inhibit the growth of inflammatory lesions (Choi et al. 2013). Kaempferol has been isolated from $B$. pinnatum which is a medicinal herb used as drug for the antimicrobial activity (Tatsimo et al. 2012). It also inhibits the aggregation of the foam-producing cells, and these foam-producing cells increase the low-density lipoprotein oxidation ( $\mathrm{Li}$ et al. 2013). These naturally occurring compounds are also used to eliminate cholesterol and lipids from macrophages (Li et al. 2013). Therefore it can reduce the effect of atherosclerotic disorder ( $\mathrm{Li}$ et al. 2013) and toxicity of neurodegenerative Parkinson's disease (Filomeni et al. 2012). Secondary glycosidic metabolites of kaempferoid have the ability to develop products like kaempferol as anticancer, antioxidant, and anti-glycine (Al-Musayeib et al. 2011). While these metabolites not only target the tumorous cells but are also capable of minimizing the side effects of the combination of both radio- and chemotherapies (Al-Musayeib et al. 2011). Productivity of kaempferol and phytochemically active compound kaempferide has a key importance to act as antiestrogenic property (Hung 2004). Photochemicals inhibit the estrogen and progesterone receptors to control the proliferation of inflammatory cancerous cells (Frigo et al. 2002). Kaempferide has structural capability to suppress the attack of fungal infections (Curir et al. 2001). It was hypothesized that kaempferol reduces the effect of vascular endothelial growth factor receptors too. VEGF receptor increases the risk of ovarian cancer; it can be controlled by taking dietary fruits and vegetables having flavonoid products (Luo et al. 2010). In vivo investigations induced the role of flavonoid kaempferide acting as an antioxidant to treat the liver patients by the use of isoforms such as P450 (Otake and Walle 2002). Another side in vitro studies show that kaempferide has anti-plasmodium and antimalarial activity against the strains of Plasmodium falciparum (De Monbrison et al. 2006). Therefore in this study it was analyzed that naturally occurring flavonol and chemically active compounds can be used as therapeutic agents. These therapeutic products play an important role to save human life and suppress the activity of various infectious diseases with the help of development of these compounds.

These plants include tea (Park et al. 2006b), broccoli, cabbage (CalderonMontano et al. 2011), and strawberries (Häkkinen et al. 1999; Calderon-Montano et al. 2011). These isolated flavonoid and chemical compounds have an antimicrobial (Yang et al. 2010), antioxidant (Choi et al. 2013), anticancer (Calderon-Montano et al. 2011), neuroprotective (Filomeni et al. 2012), antidiabetic (Habtemariam 2011), immunomodulatory (Kim et al. 2008), anti-osteoporotic, antiestrogenic (Oh et al. 2006), anxiolytic (Vissiennon et al. 2012), analgesic (Tsiklauri et al. 2011), and anti-allergic activities (Kim et al. 2008). Therefore in this study it was analyzed that naturally occurring flavonoid and chemically active compounds can be used as therapeutic agents. These therapeutic products play an important role to save human life and suppress the activity of various infectious diseases with the help of development of these compounds. 


\section{Rhamnetin and Rhamnazin}

Rhamnetin is also one of the chemical $O$-methylated flavonoid compounds (Ozipek

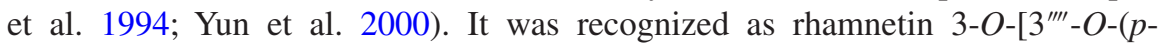
coumaroyl)-alpha-L-rhamnopyranosyl $(1 \rightarrow 3)$-alpha-L-rhamnopyranosyl $(1 \rightarrow 6)]$ beta-D-galactopyranoside (Ozipek et al. 1994). It can be isolated from various plant sources such as cloves, green vegetables, and fruits (Yun et al. 2000). Chemical structure of this natural compound has been discovered by Austrian chemist Josef Herzig. Basically this molecule having flavonol nuclei consisted of two benzene rings (Zhen et al. 2012). And these rings have been combined by $\mathrm{O}_{2}$-containing pyran rings as shown in Fig. 1 (Zhen et al. 2012).

\section{Biological Properties}

Rhamnazin was synthesized through the activity of enzyme 3-methylquercetin 7-O-methyltransferase (Khouri et al. 1988; Ozipek et al. 1994). This transferase enzyme uses $S$-adenosyl methionine and isorhamnetin to produce $S$-adenosylhomocysteine and rhamnazin (Khouri et al. 1988). Basically rhamnazin is known as 3,5-dihydroxy-2-(4-hydroxy-3-methoxyphenyl)-7-methoxychromen4-one (Khouri et al. 1988). It is also the naturally occurring 3',7-dimethylquercetin flavonoid compound (Joe et al. 2010). Like other naturally occurring chemical compounds, rhamnetin and rhamnazin also have anticancerous (Lee et al. 2011; Ma et al. 2012), antioxidant (Pande 2001), and anti-infectious activities (Ahmed et al. 2001), etc. The $O$-methylated flavonoid compounds are chemically methylated on hydroxyl groups. Chemical formation of this methoxy bond is difficult because methoxylation is possible in any position of molecule (Lee et al. 2011). So the usage of specific enzyme $O$-methyltransferase plays an important role which interacts substrate on specific position of molecule (Mattarei et al. 2010). That enzyme implies the $O$-methylation on a specific hydroxyl (3-OH) position. Multile hydroxal functional groups greatly contribute towards the therapeutic potential of polyphenols (Mattarei et al. 2010). In the metabolism these substrate molecules are rapidly being converted into sulfates, glucuronides, and methyl ethers (Biasutto et al. 2007;

Fig. 1 Core structure of flavonols

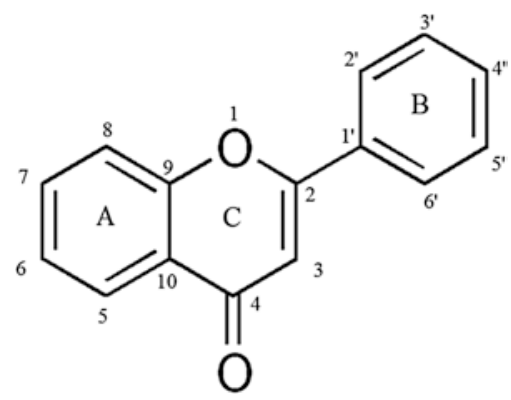


Mattarei et al. 2010). The effect of $O$-methylation depends on the solubility of flavonoids (Mattarei et al. 2010). In vivo experiments induced that chemical modification of these molecules were to enhance the solubility effect while reduces the metabolic effects to provide the low bioavailability of polyphenols (Biasutto et al. 2007; Manach et al. 2005; Silberberg et al. 2006; Williamson and Manach 2005). These studies observed the overall survival of polyphenol OHs (Mattarei et al. 2010). As shown in Fig. 1, structurally rhamnetin is a monoethyl ether of quercetin while rhamnazin is identified as quercetin dimethyl ether (Martini et al. 2004). Therapeutic potential could be attributed to functional groups i.e. C-ring of 3'-hydroxyl and 4'-hydroxyl groups contribute towards redox activity (Metodiewa et al. 1999), while 3-OH act as inhibitor (Sarno et al. 2002). On the other hand, 7-OH and 5-OH are having weak and less acidic activity because of intramolecular hydrogen bonding to the 4-carbon of carbonyl compound (Van Dijk et al. 2000). This study reports that acetylated 3-OH bond has enzymatic activity and is used as protective chemical reaction of catecholic OHs (Mattarei et al. 2010). They also suggest that this mitochondrial-targeted compound has a free $\mathrm{OH}$ at the specific 3-position (Mattarei et al. 2010).

\section{Quercetin}

Quercetin is one of the major dietary flavonoids. It is present in various plant parts including fruits, vegetables, and beans. Although exact concentration of quercetin in food stuff is not known, it is estimated that it makes 50\% of the total dietary flavonoids. Depending on various factors including plant varieties, growth conditions, processing, etc., quercetin content may vary, but onions are experimentally shown to have highest concentrations of quercetin, i.e., about $200-600 \mathrm{mg} / \mathrm{kg}$.

Quercetin contains five hydroxyl residues which are responsible for its activity and possible derivatives. Quercetin has two main groups of derivatives, i.e., glycosides and ethers. Some quercetin derivatives also contain sulfate and prenyl substituents but they are less frequent (Williams and Grayer 2004).

Quercetin $O$-glycosides are widely distributed in plants. They may either contain one or two $O$-glycoside residues. The most common derivative is quercetin 3-O-glycosides which contain $\mathrm{OH}$-group at $\mathrm{C}-3$ carbon. The commonly found sugar residues in quercetin 3-O-glycoside derivatives include glucose, galactose, rhamnose, and xylose. Another derivative is quercetin 7-O-glucoside which contains glucose residue at the hydroxyl group of C-7 carbon (Chang and Wong 2004).

Quercetin ethers make the second major group of quercetin derivatives. They may contain up to five ether bonds along with other substituents such as sugar residues and alkyl groups. Quercetin molecules are lipophilic but become hydrophilic by the glycosidation of at least one OH-group (Materska 2008). 


\section{Biological Properties}

Quercetin is an ubiquitous antioxidant and is shown beneficial in maintaining good health. Quercetin acts as anticancer agent by regulating cell cycle human breast cancer MCF-7 cells (Chou et al. 2010). Antiviral activity of quercetin has been reported against various viral trains along with other flavonoids (Cody et al. 1986). Pharmacologic effects of quercetin in various diseases including neurodegenerative disorders, cardiovascular diseases, inflammation, bacterial and fungal infections, and liver disorders have also been reported (Tanwar and Modgil 2012).

\section{Morin}

Morin (2',3,4',5,7-pentahydroxyflavone) is a yellow-colored naturally occurring substance in Maclura tinctoria (old fustic) and Maclura pomifera (Osage orange) wood and from Psidium guajava (common guava) leaves (Rattanachaikunsopon and Phumkhachorn 2007). By the circular dichroism spectrum, the change in both confirmations after the binding of morin with high affinity to site II (subdomain IIIA) of bovine serum albumin (BSA) has been observed (Hu et al. 2012).

Morin having comparatively high bimolecular rate constant $\left(k_{2}\right)$ value for its interaction with the 1,4-dinitrobenzene (1,4-DNB) electrochemical system presents to its less intermolecular hydrogen bonding and more acidic nature (Arshad et al. 2012). Circular dichroism (CD) and UV-vis spectroscopy results showed that the binding of bovine serum albumin (BSA) to morin and other flavonol compounds induces some conformational changes in BSA (Shahabadi and Mohammadpour 2012).

\section{Biological Properties}

Morin is known to have the antihypertensive and antioxidant effects in deoxycorticosterone acetate (DOCA)-salt-induced hypertension in rats (Prahalathan et al. 2012a, b). Morin has found its role in the treatment of many diseases. A significant interaction of flavonoid drug or flavonoid xenobiotic has been observed during test regarding to b5 reductase inhibition that shows a promising role in therapeutic and toxicological outcomes for certain drugs and xenobiotic (Çelik and Koşar 2012; Çelik et al. 2013). In cases of colon cancer and hepatocellular carcinoma, $3,5,7,2^{\prime}, 4^{\prime}$-pentahydroxyflavone has been observed to possess chemopreventive potential in animal models. Antiproliferative and anticarcinogenic effects also have been determined against 7,12-dimethylbenz( $(a)$-anthracene (DMBA)-induced experimental mammary carcinogenesis (Nandhakumar et al., 2012). In tumor cells, downregulation of STAT3-dependent hemosensitization and gene expression was led by the suppression of the signal transducer and activator of transcription 3 (STAT3) pathway after the application of morin (Gupta et al. 2012). 
Morin inhibited the expression of matrix metalloproteinase-3 (MMP-3) and matrix metalloproteinase-13 (MMP-13), and it also has increased the expression of tissue inhibitors of metalloproteinase-1 (TIMP-1) in interleukin-1 $\beta$ (IL-1 $\beta$ ) which induced rat chondrocytes (Chen et al. 2012a). Morin has decreased in asymmetric dimethylarginine (ADMA) level, while dimethylarginine dimethylaminohydrolase (DDAH) activity in the liver was significantly higher in rats (Merwid-Ląd et al. 2013). Morin is also been reported to be indirectly involved in insuline signalling and functionality (Paoli et al. 2013).

In vivo study in murine model, for osteoarthritis (OA) induced by anterior cruciate ligament transection (ACLT), the results clearly indicated suppression of cartilage degradation by orally administered morin. So morin has been observed to be used for the treatment of osteoarthritis (OA) as therapeutic agent (Chen et al. 2012a). Human inhibits the formation of amyloid by hydrate of morin $\left(2^{\prime}, 3,4^{\prime}, 5,7\right.$-pentahyd roxyflavone). The polypeptide hormone islet amyloid polypeptide (IAPP, amylin) and disaggregates preformed IAPP amyloid fibers observed under right-angle light scattering and transmission electron microscopy (TEM) (Noor et al. 2012). Nitric oxide (NO) and prostaglandin E2 (PGE-2) production was inhibited by morin as well as the expression of inducible NO synthase (iNOS) and cyclooxygenase (COX2 ) in interleukin-1-beta (IL-1 $\beta$ )-induced chondrocytes. Morin also suppressed the degradation of inhibitor of nuclear factor- $\kappa \mathrm{B}(\mathrm{I} \kappa \mathrm{B}-\alpha)$ as well as the translocation of nuclear factor kappa B (NF-kappa B).

In rats, an IL-1 $\beta$-induced osteoarthritis (OA) model, morin also exerted antiinflammatory properties during in vivo study (Chen et al. 2012b). Morin exhibits antioxidant potential and offers enhancement in antioxidant levels simultaneously showing protection that clearly reduce in urea, ammonia, lipid peroxidation (Subash and Subramanian 2009). It has also been clarified that a lower concentration of morin in carcinomas than normal oral mucosa inhibited the activation of activated protein kinase AKT, whereas Jun N-terminal kinase (JNK), p38 kinase, and polyclonal antibodies (GADD45) all induced the same dose-response parallel curves in normal oral mucosa and carcinomas (Brown et al. 2003).

\section{Myricetin}

Myricetin (3,5,7-trihydroxy-2-(3,4,5-trihydroxyphenyl)chromen-4-one) (figure) is a major plant secondary metabolite; these are commonly found particularly in the whole plant kingdom and in majority of human foods, i.e., different fruits, berries, grapes, herbs, vegetables, and many other plants. A rich source of myricetin is walnuts; traces can be found as glycosides (Miean and Mohamed 2001b).

Myricetin is one of the phenolic compounds which are found in red wine (Maggiolini et al. 2005). It is found on the leaf surface of wild tomato (Solanum habrochaites) plants that contain 3,7,3',5'-tetramethyl myricetin, 3,7,3'-trimethyl myricetin, and $3,7,3^{\prime}, 4^{\prime}, 5^{\prime}$-pentamethyl myricetin, with secreting glandular trichomes (gland types 1 and 4 ) containing abundantly than storage glandular tri- 
chomes (type 6) and with the tetramethylated compound predominating in all types 1, 4, and 6 (Schmidt et al. 2011). Myricetin contains a three-ring structure with a central oxygenated heterocyclic and two aromatic centers (Gee and Johnson 2001) that serve as multiple functions like antioxidant activities and pigmentation (Hertog et al. 1994).

\section{Biological Properties}

Myricetin and other polyphenolic compounds are absorbed in human gut, remaining larger fraction in the lumen, thus the major proportion of mucosa from gastrointestinal. These compounds also show considerable biological effects at cellular level. These myricetin with some other phenolic compounds control the cellular cycles, apoptosis (programmed cell death), and differentiation after interaction with cellular signal pathways (Gee and Johnson 2001). A wide range of bioactivities have been reported for this molecule i.e. Allelochemic; Antioxidant; Antibacterial; Anti-feedant; Anti-HIV; Antihistaminic; Anti-gingivitic; Antiallergenic; Antigastric; Anti-gonadotrophic; COMP-Inhibitor; Antihistaminic; Antiseptic; Antiinflammatory; Anti-mutagenic; Anti-periodontic; Antiplaque; Antiviral; Diuretic;Topoisomerase-I-Inhibitor; Hypoglycemic; Vasodilator; CancerPreventive; Mutagenic; Candidicide; Larvistat; Lipoxygenase-Inhibitor; OxidaseInhibitor; Quinone-Reductase-Inducer; Pesticide; Tyrosine-Kinase-Inhibitor; Topoisomerase-II-Inhibitor (http://www.ars-grin.gov/duke/, accessed).

Myricetin can cause muscle paralysis by inhibiting acetylcholine release at the neuromuscular junction. When compared to Clostridium botulinum neurotoxin (BoNT/A) the myricetin effect on muscle paralysis was unpretentious (Yang et al. 2011c). It is also claimed myricetin has antibiotic effects on $R$. leguminosarum bv trifolii (Fottrell et al. 1964). Myricetin is known to have DNA damage (strand breakdown and oxidized pyrimidines/purines) effect in human hepatocellular carcinoma (HepG2) cells which is induced by taking it as a diet to have a significant protective effect against $N$-nitrosopyrrolidine (NPYR)-, $N$-nitrosodimethylamine (NDMA)-, and benzo(a)pyrene (BaP)-induced DNA damage (Delgado et al. 2008). Myricetin and rosmarinic acid are inhibited by amyloid- $\beta(\mathrm{A} \beta)$ protein, and by sitespecific binding, there were also observed aggregation and synaptic dysfunction (Ono et al. 2012).

As for the role of myricetin in cancer, myricetin and scutellarin are potently shown to inhibit the severe acute respiratory syndrome coronavirus (SARS-CoV) helicase protein (Yu et al. 2012). Myricetin has been found to protect neurons' discrete and multiple pathways and inhibited glutamate-induced excitotoxicity (Shimmyo et al. 2008). Myricetin was exerted as potent chemopreventive activity mainly by targeting activity of Fyn kinase straightly and afterward attenuated UVBinduced cyclooxygenase-2 (COX-2) expression (skin carcinogenesis) (Jung et al. 2008). Myricetin $(20 \mu \mathrm{M})$ when treated with macrophages derived from U937 has been significantly observed to inhibit the expression of mRNA and surface protein CD36 cells, which means myricetin might play an important role in ameliorating 
atherosclerosis (Lian et al. 2008). During the experimental result of Perls' iron staining, it has made an evidence in the substantial nigra by the enhancement of iron-staining cells; myricetin prevented the 6-hydroxydopamine (6-OHDA) (Ma et al. 2007b). It has also been observed that antiproliferative potential of flavonoids decreased in the order isorhamnetin $>$ kaempferol $>$ myricetin $>$ rutin, while their antioxidant properties decreased in the order rutin $>$ myricetin $>$ kaempferol $>$ isorhamnetin. When combined the treatment of isorhamnetin, kaempferol, and myricetin with $\mathrm{AraC}$ has led to synergism in their antiproliferative activities (Nadova et al. 2007).

However, the result of myricetin on pharmacokinetics of carvedilol has not been reported in vivo. The enhanced oral bioavailability of carvedilol may result from both inhibition of CYP2C9 or CYP2D6-mediated metabolism and P-gp-mediated efflux of carvedilol in the small intestine and/or in liver by myricetin rather than reducing renal elimination (Lee et al. 2012).

\section{Natsudaidain}

Natsudaidain (2-(3,4-dimethoxyphenyl)-3-hydroxy-5,6,7,8-tetramethoxychromen4-one) was isolated from Citrus reticulata for the first time (Qian and Chen 1998). The name of the molecule comes from Citrus natsudaidai (Natsumikan, lit. "summer tangerine") (Matsui et al. 2009).

\section{Biological Properties}

Natsudaidain exhibited less inhibitory effect on the pro-matrix metalloproteinase-9 (proMMP-9)/in HT-1080 cells and progelatinase B production (Miyata et al. 2008). Natsudaidain has been shown to inhibit cyclooxygenase- 2 and tumor necrosis factor-alpha production by p38 MAPK phosphorylation suppression, while there was no p65 NF-kappa B phosphorylation suppression observed, and that inflammatory diseases were also mitigated by natsudaidain (Matsui et al. 2009).

Two flavonoids, natsudaidain isolated and 3,5,6,7,8,3', $4^{\prime}$ heptamethoxyflavone (HEPTA) that are extracted from Citrus plants, in guinea pig papillary muscle produced a positive inotropic effect (PIE). It has also been observed (pD2 $4.98 \pm 0.07$ ) that natsudaidain was more intense than (pD2 $4.33 \pm 0.08)$ HEPTA (Itoigawa et al. 1994). Hydroxyl C-3 and C-8 methoxyl groups were necessary for efficient activity of natsudaidain and other flavonols; on the other hand in B-ring ortho-catechol moiety and C-2, C-3 bonds were essential for the antiproliferative activity (Kawaii et al. 1999a). Natsudaidain when treated with HL 60 cells in dose-dependent manner has exerted its activity as to differentiate into repertoire of macrophage and monocytes (Kawaii et al. 1999b). 


\section{Drug Leads and Pharmacophores from Flavonols}

Association of different bioactivities to flavonols has triggered computational studies to study and understand the mechanisms and interactions involved for obtaining new drug leads. Such studies involved molecular docking, three-dimensional structure-activity relationship, and pharmacophore modeling. Investigations have reported the interactions and pharmacophoric models for flavonols based on their interactions with cellular proteins. Using theoretical and computational approaches and the antioxidant activity of structure-activity relationship of flavonoids has been calculated (Butkovic et al. 2004; Ghiotto et al. 2004; Lee et al. 2009; Om and Kim 2008; Teixeira et al. 2005). A pharmacophore map based on flavonols suggested anti-angiogenic and thus antitumor drug leads as human vascular endothelial growth factor receptor 2 (hVEGFR2) antagonists (Yang et al. 2008). Therapeutic potential of flavonoids has been explained for genetic/metabolic disorders (i.e. xanthinuria, gout, and diabetes mellitus by inhibition of respective enzymes xanthine oxidase, aldose reductase, and liposygenase), but also for viral infections as well using computational approaches (Alves et al. 2001; Liu et al. 2012).

A study focused on inhibition of hVEGFR2 signaling for antitumor effects developed receptor-based pharmacophore model using crystal structures of inhibitor-hVEGFR2 complex and cyclin-dependent kinase 6 (CDK6) and flavonoid fisetin complex. Superimposition of these complexes helped in the identification of interactions between fisetin and hVEGFR2 and resulted in pharmacophore map. Hydrogen bond acceptors (HBAs), hydrogen bond donors (HBDs), and lipophilicity (Lipo) features were used to conclude the map. Resultant map had four features, two HBD, one Lipo, and one HBA. Virtual screening was performed, and the model yielded five out of nine hits with each hit flavonol having hydrogen bonding 3- and 4'-OH interacting with ATP binding site of hVEGFR2 (Yang et al. 2008).

A NS5B inhibitor pharmacophore model (Hypo 1) was developed using common feature-based pharmacophore and structure-based docking approaches for identification of novel antivirals for HCV. Discovery Studio's Common Feature pharmacophore generation protocol was used to develop the model with best conformational generation choice. The model was evaluated using decoy set of 1040 molecules of which 40, active against NS5B, were selected from the literature, while 1000 were randomly selected may bridge database. The model Hypo 1 was used to screen in-house database commercially available natural products with 3D structures and yielded 246 hits. These hits were investigated by docking studies and the list was reduced to 31 . These results were validated in wet lab and showed inhibition of NS5B HCV enzyme (Liu et al. 2012). 


\section{Conclusions}

Attaining the spotlight since the 2000s, flavonols have been rigorously investigated for exploring their roles in metabolism, as antioxidant and also as potential drug leads. Being natural products, these are considered as much safer than the other pharmaceutical products. Current studies are focusing on evaluating the effects of flavonols on human/mammalian cells for developing more effective therapeutic agents. Sophisticated and sensitive techniques have enabled us to mine out and exploit more and more information shedding lights on curing of diseases. Multiple studies conducted have revealed the possibilities of flavonoids as leading to improved drugs for most of the clinically difficult to treat diseases in future.

\section{References}

Abdel-Rahim E, El-Beltagi HS (2010) Constituents of apple, parsley and lentil edible plants and their therapy treatments for blood picture as well as liver and kidneys functions against lipidemic disease. EJEAFChe 9(6):1117-1127

Aherne SA, O'Brien NM (2002) Dietary flavonols: chemistry, food content, and metabolism. Nutrition 18(1):75-81

Ahmed MS, Galal AM, Ross SA, Ferreira D, Elsohly MA, Ibrahim AS, Mossa JS, El-Feraly FS (2001) A weakly antimalarial biflavanone from Rhus retinorrhoea. Phytochemistry 58(4):599-602

Al-Musayeib N, Perveen S, Fatima I, Nasir M, Hussain A (2011) Antioxidant, anti-glycation and anti-inflammatory activities of phenolic constituents from Cordia sinensis. Molecules 16(12):10214-10226

Alves C, Pinheiro J, Camargo A, Ferreira M, Romero R, Da Silva A (2001) A multiple linear regression and partial least squares study of flavonoid compounds with anti-HIV activity. J Mol Struct THEOCHEM 541(1):81-88

Anderson G (2004) Phytochemicals. Dynamic Chiropractics, vol 2.

Arai Y, Watanabe S, Kimira M, Shimoi K, Mochizuki R, Kinae N (2000) Dietary intakes of flavonols, flavones and isoflavones by Japanese women and the inverse correlation between quercetin intake and plasma LDL cholesterol concentration. J Nutr 130(9):2243-2250

Arshad N, Janjua N, Khan A, Yaqub A, Burkholz T, Jacob C (2012) Natural flavonoids interact with dinitrobenzene system in aprotic media: an electrochemical probing. Nat Prod Commun 7(3):311

Babu B, Jayram H, Nair M, Ajaikumar K, Padikkala J (2003) Free radical scavenging, antitumor and anticarcinogenic activity of gossypin. J Exp Clin Cancer Res 22(4):581-590

Bertoncelj J, Polak T, Kropf U, Korošec M, Golob T (2011) LC-DAD-ESI/MS analysis of flavonoids and abscisic acid with chemometric approach for the classification of Slovenian honey. Food Chem 127(1):296-302

Biasutto L, Marotta E, De Marchi U, Zoratti M, Paradisi C (2007) Ester-based precursors to increase the bioavailability of quercetin. J Med Chem 50(2):241-253

Boesch-Saadatmandi C, Loboda A, Wagner AE, Stachurska A, Jozkowicz A, Dulak J, Döring F, Wolffram S, Rimbach G (2011) Effect of quercetin and its metabolites isorhamnetin and quercetin-3-glucuronide on inflammatory gene expression: role of miR-155. J Nutr Biochem 22(3):293-299

Bohm BA, Stuessy TF (2001) Flavonoids of the sunflower family (Asteraceae). Springer, Wien 
Bouhlel I, Skandrani I, Nefatti A, Valenti K, Ghedira K, Mariotte AM, Hininger-Favier I, Laporte F, Dijoux-Franca MG, Chekir-Ghedira L (2009) Antigenotoxic and antioxidant activities of isorhamnetin 3-O neohesperidoside from Acacia salicina. Drug Chem Toxicol 32(3):258-267

Brown J, O'Prey J, Harrison P (2003) Enhanced sensitivity of human oral tumours to the flavonol, morin, during cancer progression: involvement of the Akt and stress kinase pathways. Carcinogenesis 24(2):171-177

Butkovic V, Klasinc L, Bors W (2004) Kinetic study of flavonoid reactions with stable radicals. J Agric Food Chem 52(10):2816-2820

Calderon-Montano JM, Burgos-Moron E, Perez-Guerrero C, Lopez-Lazaro M (2011) A review on the dietary flavonoid kaempferol. Mini Rev Med Chem 11(4):298-344

Campana R, Patrone V, Franzini ITM, Diamantini G, Vittoria E, Baffone W (2009) Antimicrobial activity of two propolis samples against human Campylobacter jejuni. J Med Food 12(5):1050-1056

Çelik H, Koşar M (2012) Inhibitory effects of dietary flavonoids on purified hepatic NADHcytochrome b5 reductase: structure-activity relationships. Chem Biol Interact 197:103-109

Çelik H, Koşar M, Arinç E (2013) In vitro effects of myricetin, morin, apigenin, (+)-taxifolin, (+)-catechin, (-)-epicatechin, naringenin and naringin on cytochrome b5 reduction by purified NADH-cytochrome b5 reductase. Toxicology 308:34-40

Chang BS, Lowenstein DH (2003) Practice parameter: antiepileptic drug prophylaxis in severe traumatic brain injury: report of the Quality Standards Subcommittee of the American Academy of Neurology. Neurology 60(1):10-16

Chang Q, Wong Y-S (2004) Identification of flavonoids in Hakmeitau beans (Vigna sinensis) by high-performance liquid chromatography-electrospray mass spectrometry (LC-ESI/MS). J Agric Food Chem 52(22):6694-6699

Chen AY, Chen YC (2013) A review of the dietary flavonoid, kaempferol on human health and cancer chemoprevention. Food Chem 138(4):2099-2107

Chen H, Li L, Zhou M, Ma YJ (2008) Flow-injection chemiluminescence determination of tryptophan using galangin-potassium permanganate-polyphosphoric acid system. Chin Chem Lett 19(2):203-206

Chen W-P, Hu P-F, Bao J-P, Wu L-D (2012a) Morin exerts antiosteoarthritic properties: an in vitro and in vivo study. Exp Biol Med 237(4):380-386

Chen W-P, Wang Y-L, Tang J-L, Hu P-F, Bao J-P, Wu L-D (2012b) Morin inhibits interleukin$1 \beta$-induced nitric oxide and prostaglandin E2 production in human chondrocytes. Int Immunopharmacol 12(2):447-452

Choi K-C, Chung W-T, Kwon J-K, Yu J-Y, Jang Y-S, Park S-M, Lee S-Y, Lee J-C (2010) Inhibitory effects of quercetin on aflatoxin $\mathrm{B}_{1}$-induced hepatic damage in mice. Food Chem Toxicol 48(10):2747-2753

Choi IS, Choi EY, Jin JY, Park HR, Choi JI, Kim SJ (2013) Kaempferol inhibits P. intermedia lipopolysaccharide-induced production of nitric oxide through translational regulation in murine macrophages: critical role of heme oxygenase-1-mediated ROS reduction. J Periodontol 84(4):545-555

Chou C-C, Yang J-S, Lu H-F, Ip S-W, Lo C, Wu C-C, Lin J-P, Tang N-Y, Chung J-G, Chou M-J (2010) Quercetin-mediated cell cycle arrest and apoptosis involving activation of a caspase cascade through the mitochondrial pathway in human breast cancer MCF-7 cells. Arch Pharm Res 33(8):1181-1191

Cody V, Middleton E, Harborne JB (1986) Plant flavonoids in biology and medicine: biochemical, pharmacological, and structure-activity relationships: proceedings of a symposium held in Buffalo, New York, July 22-26, 1985. Liss, New York

Constantin RP, Constantin J, Pagadigorria CLS, Ishii-Iwamoto EL, Bracht A, Ono MDKC, Yamamoto NS (2010) The actions of fisetin on glucose metabolism in the rat liver. Cell Biochem Funct 28(2):149-158 
Curir P, Dolci M, Lanzotti V, Taglialatela-Scafati O (2001) Kaempferide triglycoside: a possible factor of resistance of carnation (Dianthus caryophyllus) to Fusarium oxysporum f. sp. dianthi. Phytochemistry 56(7):717-721

Cushnie T (2006) Investigation of the antibacterial activity of selected flavonoids. Robert Gordon University, Aberdeen

Cushnie T, Lamb A (2006) Assessment of the antibacterial activity of galangin against 4-quinolone resistant strains of Staphylococcus aureus. Phytomedicine 13(3):187-191

De Monbrison F, Maitrejean M, Latour C, Bugnazet F, Peyron F, Barron D, Picot S (2006) In vitro antimalarial activity of flavonoid derivatives dehydrosilybin and 8-(1;1)-DMA-kaempferide. Acta Trop 97(1):102-107

Delgado ME, Haza AI, Arranz N, García A, Morales P (2008) Dietary polyphenols protect against $\mathrm{N}$-nitrosamines and benzo (a) pyrene-induced DNA damage (strand breaks and oxidized purines/pyrimidines) in HepG2 human hepatoma cells. Eur J Nutr 47(8):479-490

El-Shobaki F, El-Bahay A, Esmail R, El-Megeid A, Esmail N (2010) Effect of figs fruit (Ficus carica L.) and its leaves on hyperglycemia in alloxan diabetic rats. World J Dairy Food Sci $5(1): 47-57$

Ferrandiz M, Alcaraz M (1991) Anti-inflammatory activity and inhibition of arachidonic acid metabolism by flavonoids. Agents Actions 32(3-4):283-288

Filomeni G, Graziani I, De Zio D, Dini L, Centonze D, Rotilio G, Ciriolo MR (2012) Neuroprotection of kaempferol by autophagy in models of rotenone-mediated acute toxicity: possible implications for Parkinson's disease. Neurobiol Aging 33(4):767-785

Fisher RS, Boas WVE, Blume W, Elger C, Genton P, Lee P, Engel J (2005) Epileptic seizures and epilepsy: definitions proposed by the International League Against Epilepsy (ILAE) and the International Bureau for Epilepsy (IBE). Epilepsia 46(4):470-472

Fottrell P, O'Connor S, Masterson C (1964) Identification of the flavonol myricetin in legume seeds and its toxicity to nodule bacteria. Irish J Agric Res 3:246-249

Frigo DE, Duong BN, Melnik LI, Schief LS, Collins-Burow BM, Pace DK, Mclachlan JA, Burow ME (2002) Flavonoid phytochemicals regulate activator protein-1 signal transduction pathways in endometrial and kidney stable cell lines. J Nutr 132(7):1848-1853

Ganapaty S, Chandrashekhar V, Narsu ML (2010) Evaluation of anti-allergic activity of gossypin and suramin in mast cell-mediated allergy model. Indian J Biochem Biophys 47:90-95

Gardana C, Scaglianti M, Pietta P, Simonetti P (2007) Analysis of the polyphenolic fraction of propolis from different sources by liquid chromatography-tandem mass spectrometry. J Pharm Biomed Anal 45(3):390-399

Gautam P, Flora S (2010) Oral supplementation of gossypin during lead exposure protects alteration in heme synthesis pathway and brain oxidative stress in rats. Nutrition 26(5):563-570

Gautam A, Vijayaraghavan R (2007) Prophylactic effect of gossypin against percutaneously administered sulfur mustard. Biomed Environ Sci 20(3):250

Gee J, Johnson I (2001) Polyphenolic compounds: interactions with the gut and implications for human health. Curr Med Chem 8(11):1245-1255

Ghiotto R, Lavarda F, Ferreira F (2004) Antioxidant activity of flavonols. Int J Quant Chem 97(5):949-952

Gohar AA, Maatooq GT, Niwa M (2000) Two flavonoid glycosides from Chenopodium murale. Phytochemistry 53(2):299-303

Grippi F, Crosta L, Tolomeo M, Aiello G, D'Amico R, Gebbia N, Curione A, Capasso A (2007) Detection of polyphenolic compounds (stilbenes and flavonoids) in natural products. Recent Dev Med Plant Res. 393-404

Gryglewski RJ, Korbut R, Robak J, Święs J (1987) On the mechanism of antithrombotic action of flavonoids. Biochem Pharmacol 36(3):317-322

Gupta SC, Kim JH, Prasad S, Aggarwal BB (2010) Regulation of survival, proliferation, invasion, angiogenesis, and metastasis of tumor cells through modulation of inflammatory pathways by nutraceuticals. Cancer Metastasis Rev 29(3):405-434 
Gupta SC, Phromnoi K, Aggarwal BB (2013) Morin inhibits STAT3 tyrosine 705 phosphorylation in tumor cells through activation of protein tyrosine phosphatase SHP1. Biochem Pharmacol 85:898-912

Gwak J, Oh J, Cho M, Bae SK, Song I-S, Liu K-H, Jeong Y, Kim D-E, Chung Y-H, Oh S (2011) Galangin suppresses the proliferation of $\beta$-catenin response transcription-positive cancer cells by promoting adenomatous polyposis coli/Axin/glycogen synthase kinase-3 $\beta$-independent $\beta$-catenin degradation. Mol Pharmacol 79(6):1014-1022

Habtemariam S (2011) A-glucosidase inhibitory activity of kaempferol-3-O-rutinoside. Nat Prod Commun 6(2):201-203

Hakkinen SH, Karenlampi SO, Heinonen IM, Mykkanen HM, Torronen AR (1999) Content of the flavonols quercetin, myricetin, and kaempferol in 25 edible berries. J Agric Food Chem 47(6):2274-2279

Häkkinen SH, Kärenlampi SO, Heinonen IM, Mykkänen HM, Törrönen AR (1999) Content of the flavonols quercetin, myricetin, and kaempferol in 25 edible berries. J Agric Food Chem 47(6):2274-2279

Havaux M, Kloppstech K (2001) The protective functions of carotenoid and flavonoid pigments against excess visible radiation at chilling temperature investigated in Arabidopsis npq and tt mutants. Planta 213(6):953-966

Havsteen BH (2002) The biochemistry and medical significance of the flavonoids. Pharmacol Ther 96(2):67-202

Heo MY, Sohn SJ, Au WW (2001) Anti-genotoxicity of galangin as a cancer chemopreventive agent candidate. Mutat Res/Rev Mutat Res 488(2):135-150

Hertog MG, Feskens EJ, Hollman PC, Katan MB, Kromhout D (1994) Dietary flavonoids and cancer risk in the Zutphen Elderly Study. Nutr Cancer 22:175-184

Hill S, Williams KB, Denekamp J (1989) Vascular collapse after flavone acetic acid: a possible mechanism of its anti-tumour action. Eur J Cancer Clin Oncol 25(10):1419-1424

Hu Y-J, Yue H-L, Li X-L, Zhang S-S, Tang E, Zhang L-P (2012) Molecular spectroscopic studies on the interaction of morin with bovine serum albumin. J Photochem Photobiol B: Biol $112: 16-22$

Hung H (2004) Inhibition of estrogen receptor alpha expression and function in MCF-7 cells by kaempferol. J Cell Physiol 198(2):197-208

Ibarra M, Pérez-Vizcaíno F, Cogolludo A, Duarte J, Zaragozá-Arnáez F, López-López JG, Tamargo $\mathrm{J}$ (2002) Cardiovascular effects of isorhamnetin and quercetin in isolated rat and porcine vascular smooth muscle and isolated rat atria. Planta Med 68(04):307-310

Ibrahim LF, Kawashty SA, El-Hagrassy AM, Nassar MI, Mabry TJ (2008) A new kaempferol triglycoside from Fagonia taeckholmiana: cytotoxic activity of its extracts. Carbohydr Res 343(1):155-158

Ishige K, Schubert D, Sagara Y (2001) Flavonoids protect neuronal cells from oxidative stress by three distinct mechanisms. Free Radic Biol Med 30(4):433-446

Itoigawa M, Takeya K, Furukawa H (1994) Cardiotonic flavonoids from Citrus plants (Rutaceae). Biol Pharm Bull 17(11):1519-1521

Jaramillo S, Lopez S, Varela LM, Rodriguez-Arcos R, Jimenez A, Abia R, Guillen R, Muriana FJ (2010) The flavonol isorhamnetin exhibits cytotoxic effects on human colon cancer cells. J Agric Food Chem 58(20):10869-10,875

Joe EJ, Kim BG, An BC, Chong Y, Ahn JH (2010) Engineering of flavonoid O-methyltransferase for a novel regioselectivity. Mol Cells 30(2):137-141

Jung SK, Lee KW, Byun S, Kang NJ, Lim SH, Heo Y-S, Bode AM, Bowden GT, Lee HJ, Dong Z (2008) Myricetin suppresses UVB-induced skin cancer by targeting Fyn. Cancer Res 68(14):6021-6029

Kawaii S, Tomono Y, Katase E, Ogawa K, Yano M (1999a) Antiproliferative activity of flavonoids on several cancer cell lines. Biosci Biotechnol Biochem 63(5):896-899

Kawaii S, Tomono Y, Katase E, Ogawa K, Yano M (1999b) Effect of citrus flavonoids on HL-60 cell differentiation. Anticancer Res 19(2A):1261 
Khalil M, Sulaiman S (2010) The potential role of honey and its polyphenols in preventing heart disease: a review. Afr J Tradit Complement Altern Med 7(4):315-321

Khouri HE, De Luca V, Ibrahim RK (1988) Enzymatic synthesis of polymethylated flavonols in Chrysosplenium americanum. III. Purification and kinetic analysis of S-adenosyl-Lmethionine:3-methylquercetin 7-O-methyltransferase. Arch Biochem Biophys 265(1):1-7

Kim HY, Kim OH, Sung MK (2003) Effects of phenol-depleted and phenol-rich diets on blood markers of oxidative stress, and urinary excretion of quercetin and kaempferol in healthy volunteers. J Am Coll Nutr 22(3):217-223

Kim DS, Ha KC, Kwon DY, Kim MS, Kim HR, Chae SW, Chae HJ (2008) Kaempferol protects ischemia/reperfusion-induced cardiac damage through the regulation of endoplasmic reticulum stress. Immunopharmacol Immunotoxicol 30(2):257-270

Kim J-E, Lee D-E, Lee KW, Son JE, Seo SK, Li J, Jung SK, Heo Y-S, Mottamal M, Bode AM (2011) Isorhamnetin suppresses skin cancer through direct inhibition of MEK1 and PI3K. Cancer Prev Res 4(4):582-591

Kim TH, Ku SK, Lee IC, Bae JS (2012) Anti-inflammatory effects of kaempferol-3-O-sophoroside in human endothelial cells. Inflamm Res 61(3):217-224

Kunnumakkara AB, Nair AS, Ahn KS, Pandey MK, Yi Z, Liu M, Aggarwal BB (2007) Gossypin, a pentahydroxy glucosyl flavone, inhibits the transforming growth factor beta-activated kinase1-mediated NF-kB activation pathway, leading to potentiation of apoptosis, suppression of invasion, and abrogation of osteoclastogenesis. Blood 109(12):5112-5121

Landi-Librandi AP, De Oliveira CA, Caleiro Seixas Azzolini AE, Mariko Kabeya L, Del Ciampo JO, Lopes Badra Bentley MV, Lucisano-Valim YM (2011) In vitro evaluation of the antioxidant activity of liposomal flavonols by the HRP-H2O2-luminol system. J Microencapsul 28(4):258-267

Lee SJ, Son KH, Chang HW, Do JC, Jung KY, Kang SS, Kim HP (1993) Antiinflammatory activity of naturally occurring flavone and flavonol glycosides. Arch Pharm Res 16(1):25-28

Lee JY, Jeong KW, Kim W, Heo YS, Kim Y (2009) Binding models of flavonols to human vascular endothelial growth factor receptor 2. Bull Korean Chem Soc 30(9):2083-2086

Lee J, Lee J, Jung E, Hwang W, Kim Y-S, Park D (2010) Isorhamnetin-induced anti-adipogenesis is mediated by stabilization of $\beta$-catenin protein. Life Sci 86(11):416-423

Lee S, Shin SY, Lee Y, Park Y, Kim BG, Ahn JH, Chong Y, Lee YH, Lim Y (2011) Rhamnetin production based on the rational design of the poplar O-methyltransferase enzyme and its biological activities. Bioorg Med Chem Lett 21(13):3866-3870

Lee W, Woo E, Choi J (2012) Effects of myricetin on the bioavailability of carvedilol in rats. Pharma Biol 50(4):516-522

Li XY, Kong LX, Li J, He HX, Zhou YD (2013) Kaempferol suppresses lipid accumulation in macrophages through the downregulation of cluster of differentiation 36 and the upregulation of scavenger receptor class B type I and ATP-binding cassette transporters A1 and G1. Int J Mol Med 31(2):331-338

Lian T-W, Wang L, Lo Y-H, Huang I-J, Wu M-J (2008) Fisetin, morin and myricetin attenuate CD36 expression and oxLDL uptake in U937-derived macrophages. Biochim Biophys Acta 1781(10):601-609

Liu M-M, Zhou L, He P-L, Zhang Y-N, Zhou J-Y, Shen Q, Chen X-W, Zuo J-P, Li W, Ye D-Y (2012) Discovery of flavonoid derivatives as anti-HCV agents via pharmacophore search combining molecular docking strategy. Eur J Med Chem 52:33-43

Lopez-Lazaro M (2002) Flavonoids as anticancer agents: structure-activity relationship study. Curr Med Chem Anticancer Agents 2(6):691-714

Luo H, Daddysman MK, Rankin GO, Jiang BH, Chen YC (2010) Kaempferol enhances cisplatin's effect on ovarian cancer cells through promoting apoptosis caused by down regulation of cMyc. Cancer Cell Int 10:16

Ma G, Yang C, Qu Y, Wei H, Zhang T, Zhang N (2007a) The flavonoid component isorhamnetin in vitro inhibits proliferation and induces apoptosis in Eca-109 cells. Chem Biol Interact 167(2):153-160 
Ma Z-G, Wang J, Jiang H, Liu T-W, Xie J-X (2007b) Myricetin reduces 6-hydroxydopamineinduced dopamine neuron degeneration in rats. Neuroreport 18(11):1181-1185

Ma H, Yuan T, Gonzalez-Sarrias A, Li L, Edmonds ME, Seeram NP (2012) New galloyl derivative from winged sumac (Rhus copallinum) fruit. Nat Prod Commun 7(1):45-46

Maggiolini M, Recchia A, Bonofiglio D, Catalano S, Vivacqua A, Carpino A, Rago V, Rossi R, Ando $S$ (2005) The red wine phenolics piceatannol and myricetin act as agonists for estrogen receptor $\alpha$ in human breast cancer cells. J Mol Endocrinol 35(2):269-281

Maher P (2006) A comparison of the neurotrophic activities of the flavonoid fisetin and some of its derivatives. Free Radic Res 40(10):1105-1111

Maher P (2008) The flavonoid fisetin promotes nerve cell survival from trophic factor withdrawal by enhancement of proteasome activity. Arch Biochem Biophy 476(2):139-144

Maher P, Dargusch R, Bodai L, Gerard PE, Purcell JM, Marsh JL (2011a) ERK activation by the polyphenols fisetin and resveratrol provides neuroprotection in multiple models of Huntington's disease. Hum Mol Genet 20(2):261-270

Maher P, Dargusch R, Ehren JL, Okada S, Sharma K, Schubert D (2011b) Fisetin lowers methylglyoxal dependent protein glycation and limits the complications of diabetes. PLoS One 6(6):e21226

Manach C, Williamson G, Morand C, Scalbert A, Remesy C (2005) Bioavailability and bioefficacy of polyphenols in humans. I. Review of 97 bioavailability studies. Am J Clin Nutr 81(1 Suppl):230S-242S

March RE, Miao XS, Metcalfe CD (2004) A fragmentation study of a flavone triglycoside, kaempferol-3-O-robinoside-7-O-rhamnoside. Rapid Commun Mass Spectrom 18(9):931-934

Markham KR, Geiger H, Jaggy H (1992) Kaempferol-3-O-glucosyl(1-2)rhamnoside from Ginkgo biloba and a reappraisal of other gluco(1-2, 1-3 and 1-4)rhamnoside structures. Phytochemistry 31(3):1009-1011

Martini ND, Katerere DR, Eloff JN (2004) Biological activity of five antibacterial flavonoids from Combretum erythrophyllum (Combretaceae). J Ethnopharmacol 93(2-3):207-212

Materska M (2008) Quercetin and its derivatives: chemical structure and bioactivity-a review. Pol J Food Nutr Sci 58(4):407-413

Matsui T, Ito C, Itoigawa M, Okada T, Furukawa H (2009) Effect of natsudaidain isolated from Citrus plants on TNF- $\alpha$ and cyclooxygenase-2 expression in RBL-2H3 cells. J Pharm Pharmacol 61(1):109-114

Mattarei A, Biasutto L, Rastrelli F, Garbisa S, Marotta E, Zoratti M, Paradisi C (2010) Regioselective O-derivatization of quercetin via ester intermediates. An improved synthesis of rhamnetin and development of a new mitochondriotropic derivative. Molecules 15(7):4722-4736

Melgarejo E, Medina M, Sánchez-Jiménez F, Botana L, Dominguez M, Escribano L, Orfao A, Urdiales J (2007) (-)-Epigallocatechin-3-gallate interferes with mast cell adhesiveness, migration and its potential to recruit monocytes. Cell Mol Life Sci 64(19-20):2690-2701

Melidou M, Riganakos K, Galaris D (2005) Protection against nuclear DNA damage offered by flavonoids in cells exposed to hydrogen peroxide: the role of iron chelation. Free Radic Biol Med 39(12):1591-1600

Méric J-B, Rottey S, Olaussen K, Soria J-C, Khayat D, Rixe O, Spano J-P (2006) Cyclooxygenase-2 as a target for anticancer drug development. Crit Rev Oncol/Hematol 59(1):51-64

Merwid-Ląd A, Trocha MG, Chlebda-Sieragowska E, Sozañski T, Magdalan J, Ksiądzyna D, Szuba A, Kopacz M, Kuÿniar A, Nowak D (2013) Effect of cyclophosphamide and morin5 '-sulfonic acid sodium salt, alone or in combination, on ADMA/DDAH pathway in rats. Pharmacol Rep 65(201):201-207

Metodiewa D, Jaiswal AK, Cenas N, Dickancaite E, Segura-Aguilar J (1999) Quercetin may act as a cytotoxic prooxidant after its metabolic activation to semiquinone and quinoidal product. Free Radic Biol Med 26(1-2):107-116

Middleton E, Kandaswami C, Theoharides TC (2000) The effects of plant flavonoids on mammalian cells: implications for inflammation, heart disease, and cancer. Pharmacol Rev 52(4):673-751 
Miean KH, Mohamed S (2001a) Flavonoid (myricetin, quercetin, kaempferol, luteolin, and apigenin) content of edible tropical plants. J Agric Food Chem 49(6):3106-3112

Miean KH, Mohamed S (2001b) Flavonoid (myricetin, quercetin, kaempferol, luteolin, and apigenin) content of edible tropical plants. J Agric Food Chem 49(6):3106-3112

Miyata T, De Strihou CVY, Imasawa T, Yoshino A, Ueda Y, Ogura H, Kominami K, Onogi H, Inagi R, Nangaku M (2001) Glyoxalase I deficiency is associated with an unusual level of advanced glycation end products in a hemodialysis patient. Kidney Int 60(6):2351-2359

Miyata Y, Sato T, Imada K, Dobashi A, Yano M, Ito A (2008) A citrus polymethoxyflavonoid, nobiletin, is a novel MEK inhibitor that exhibits antitumor metastasis in human fibrosarcoma HT-1080 cells. Biochem Biophys Res Commun 366(1):168-173

Monasterio A, Urdaci MC, Pinchuk IV, Lopez-Moratalla N, Martinez-Irujo JJ (2004) Flavonoids induce apoptosis in human leukemia U937 cells through caspase-and caspase-calpaindependent pathways. Nutr Cancer 50(1):90-100

Mukai R, Shirai Y, Saito N, Yoshida K-I, Ashida H (2009) Subcellular localization of flavonol aglycone in hepatocytes visualized by confocal laser scanning fluorescence microscope. Cytotechnology 59(3):177-182

Murray TJ, Yang X, Sherr DH (2006) Growth of a human mammary tumor cell line is blocked by galangin, a naturally occurring bioflavonoid, and is accompanied by down-regulation of cyclins D3, E, and A. Breast Cancer Res 8(2):R17

Nadova S, Miadokova E, Cipak L (2007) Flavonoids potentiate the efficacy of cytarabine through modulation of drug-induced apoptosis. Neoplasma 54(3):202

Nandhakumar R, Salini K, Devaraj SN (2012) Morin augments anticarcinogenic and antiproliferative efficacy against 7, 12-dimethylbenz (a)-anthracene induced experimental mammary carcinogenesis. Mol Cell Biochem 364(1-2):79-92

Neelakantam K, Seshadri T (1936) Pigments of cotton flowers. In: Proceedings of the Indian Academy of Sciences-section A. Springer, Basel, pp 54-58

Nijveldt RJ et al (2001) Flavonoids: a review of probable mechanisms of action and potential applications. Am J Clin Nutr 74(4):418-425

Noor H, Cao P, Raleigh DP (2012) Morin hydrate inhibits amyloid formation by islet amyloid polypeptide and disaggregates amyloid fibers. Prot Sci 21(3):373-382

Nowak S, Wolbis M (2002) Flavonoids from some species of genus Scopolia Jacq. Acta Pol Pharm 59(4):275-280

Oh HM, Kwon B-M, Baek N-I, Kim S-H, Chung I-S, Park M-H, Park HW, Lee JH, Park HW, Kim EJ (2005) Inhibitory activity of isorhamnetin from Persicaria thunbergii on Farnesyl Protein Transferase. Arch Pharm Res 28(2):169-171

Oh SM, Kim YP, Chung KH (2006) Biphasic effects of kaempferol on the estrogenicity in human breast cancer cells. Arch Pharm Res 29(5):354-362

Om A, Kim J (2008) A quantitative structure-activity relationship model for radical scavenging activity of flavonoids. J Med Food 11(1):29-37

Ono K, Li L, Takamura Y, Yoshiike Y, Zhu L, Han F, Mao X, Ikeda T, Takasaki J-I, Nishijo H (2012) Phenolic compounds prevent amyloid $\beta$-protein oligomerization and synaptic dysfunction by site-specific binding. J Biol Chem 287(18):14631-14643

Otake Y, Walle T (2002) Oxidation of the flavonoids galangin and kaempferide by human liver microsomes and CYP1A1, CYP1A2, and CYP2C9. Drug Metab Dispos 30(2):103-105

Ozipek M, Calis I, Ertan M, Ruedi P (1994) Rhamnetin 3-p-coumaroylrhamninoside from Rhamnus petiolaris. Phytochemistry 37(1):249-253

Pande V (2001) Antioxidant activity of rhamnazin-4'-O-beta-[apiosyl(1 $\rightarrow 2)$ ] glucoside in the brain of aged rats. Pharmazie 56(9):749-750

Paoli P, Cirri P, Caselli A, Ranaldi F, Bruschi G, Santi A, Camici G (2013) The insulin-mimetic effect of Morin: a promising molecule in diabetes treatment. Biochim Biophys Acta 1830:3102-3111

Park JS, Rho HS, Kim DH, Chang IS (2006a) Enzymatic preparation of kaempferol from green tea seed and its antioxidant activity. J Agric Food Chem 54(8):2951-2956 
Park JS, Rho HS, Kim DH, Chang IS (2006b) Enzymatic preparation of kaempferol from green tea seed and its antioxidant activity. J Agric Food Chem 54(8):2951-2956

Park H-H, Lee S, Son H-Y, Park S-B, Kim M-S, Choi E-J, Singh TS, Ha J-H, Lee M-G, Kim J-E (2008) Flavonoids inhibit histamine release and expression of proinflammatory cytokines in mast cells. Arch Pharm Res 31(10):1303-1311

Patrick L (2006) Lead toxicity, a review of the literature. Part 1: exposure, evaluation, and treatment. Altern Med Rev 11(1):2-22

Prahalathan P, Kumar S, Raja B (2012a) Effect of morin, a flavonoid against DOCA-salt hypertensive rats: a dose dependent study. Asian Pacific J Trop Biomed 2(6):443-448

Prahalathan P, Kumar S, Raja B (2012b) Morin attenuates blood pressure and oxidative stress in deoxycorticosterone acetate-salt hypertensive rats: a biochemical and histopathological evaluation. Metabolism 61(8):1087-1099

Prasad S, Phromnoi K, Yadav VR, Chaturvedi MM, Aggarwal BB (2010) Targeting inflammatory pathways by flavonoids for prevention and treatment of cancer. Planta Med 76(11):1044

Qian S, Chen L (1998) [Studies on the chemical constituents of Citrus reticulata]. Zhong Yao Cai 21(6):301

Ragasa CY, De Luna RD, Cruz WC Jr, Rideout JA (2005) Monoterpene lactones from the seeds of Nephelium lappaceum. J Nat Prod 68(9):1394-1396

Ramachandran L, Manu KA, Shanmugam MK, Li F, Siveen KS, Vali S, Kapoor S, Abbasi T, Surana R, Smoot DT (2012) Isorhamnetin inhibits proliferation and invasion and induces apoptosis through the modulation of peroxisome proliferator-activated receptor $\gamma$ activation pathway in gastric cancer. J Biol Chem 287(45):38028-38,040

Rao KV, Seshadri T (1946a) Colouring matter of the flowers of Hibiscus vitifolius. In: Proceedings of the Indian Academy of Sciences—section A. Springer, Basel, pp 352-356

Rao KV, Seshadri T (1946b) Constitution of gossypin - part I. In: Proceedings of the Indian Academy of Sciences—-section A. Springer, Basel, pp 375-381

Rasilingam D, Duraisamy S, Subramanian R (2008) Anticonvulsant activity of bioflavonoid gossypin. Bangladesh J Pharmacol 4(1):51-54

Rattanachaikunsopon P, Phumkhachorn P (2007) Bacteriostatic effect of flavonoids isolated from leaves of Psidium guajava on fish pathogens. Fitoterapia 78(6):434-436

Richelson LS, Wahner HW, Melton L 3rd, Riggs BL (1984) Relative contributions of aging and estrogen deficiency to postmenopausal bone loss. N Engl J Med 311(20):1273

Saavedra N, Barrientos L, Herrera C, Alvear M, Montenegro G, Salazar L (2011) Effect of Chilean propolis on cariogenic bacteria Lactobacillus fermentum. Cienc Inv Agr 38(1):117-125

Sagara Y, Vanhnasy J, Maher P (2004) Induction of PC12 cell differentiation by flavonoids is dependent upon extracellular signal-regulated kinase activation. J Neurochem 90(5):1144-1155

Šarić A, Balog T, Sobočanec S, Kušić B, Šverko V, Rusak G, Likić S, Bubalo D, Pinto B, Reali D (2009) Antioxidant effects of flavonoid from Croatian Cystus incanus L. rich bee pollen. Food Chem Toxicol 47(3):547-554

Sarno S, Moro S, Meggio F, Zagotto G, Dal Ben D, Ghisellini P, Battistutta R, Zanotti G, Pinna LA (2002) Toward the rational design of protein kinase casein kinase-2 inhibitors. Pharmacol Ther 93(2-3): 159-168

Schmidt A, Li C, Shi F, Jones AD, Pichersky E (2011) Polymethylated myricetin in trichomes of the wild tomato species Solanum habrochaites and characterization of trichome-specific 3'/5'and 7/4'-myricetin O-methyltransferases. Plant Physiol 155(4):1999-2009

Selway JT (1986) Antiviral activity of flavones and flavans. Prog Clin Biol Res 213:521

Shahabadi N, Mohammadpour M (2012) Study on the interaction of sodium morin-5-sulfonate with bovine serum albumin by spectroscopic techniques. Spectrochim Acta A Mol Biomol Spectrose 86:191-195

Shi L, Chen J, Wang Y-Y, Sun G, Liu J-N, Zhang J-X, Yan W, Qian C-F, Liu N, Fu Z (2012) Gossypin induces G2/M arrest in human malignant glioma U251 cells by the activation of Chk1/Cdc25C pathway. Cell Mol Neurobiol 32(2):289-296 
Shimmyo Y, Kihara T, Akaike A, Niidome T, Sugimoto H (2008) Three distinct neuroprotective functions of myricetin against glutamate-induced neuronal cell death: involvement of direct inhibition of caspase-3. J Neurosci Res 86(8):1836-1845

Silberberg M, Morand C, Mathevon T, Besson C, Manach C, Scalbert A, Remesy C (2006) The bioavailability of polyphenols is highly governed by the capacity of the intestine and of the liver to secrete conjugated metabolites. Eur J Nutr 45(2):88-96

Silbergeld EK, Waalkes M, Rice JM (2000) Lead as a carcinogen: experimental evidence and mechanisms of action. Am J Ind Med 38(3):316-323

Sivakumar AS, Anuradha CV (2011) Effect of galangin supplementation on oxidative damage and inflammatory changes in fructose-fed rat liver. Chem Biol Interact 193(2):141-148

Steffen Y, Gruber C, Schewe T, Sies H (2008) Mono- $O$-methylated flavanols and other flavonoids as inhibitors of endothelial NADPH oxidase. Arch Biochem Biophys 469(2):209-219

Subash S, Subramanian P (2009) Morin a flavonoid exerts antioxidant potential in chronic hyperammonemic rats: a biochemical and histopathological study. Mol Cell Biochem 327(1-2):153-161

Sultana B, Anwar F (2008) Flavonols (kaempferol, quercetin, myricetin) contents of selected fruits, vegetables and medicinal plants. Food Chem 108(3):879-884

Sung B, Pandey MK, Aggarwal BB (2007) Fisetin, an inhibitor of cyclin-dependent kinase 6, down-regulates nuclear factor- $\mathrm{kB}$-regulated cell proliferation, antiapoptotic and metastatic gene products through the suppression of TAK-1 and receptor-interacting protein-regulated IкB $\alpha$ kinase activation. Mol Pharmacol 71(6):1703-1714

Suomela J-P, Ahotupa M, Yang B, Vasankari T, Kallio H (2006) Absorption of flavonols derived from sea buckthorn (Hippophae rhamnoides L.) and their effect on emerging risk factors for cardiovascular disease in humans. J Agric Food Chem 54(19):7364-7369

Tanwar B, Modgil R (2012) Flavonoids: dietary occurrence and health benefits. Spatula DD 2(1):59-68

Tatsimo SJ, Tamokou Jde D, Havyarimana L, Csupor D, Forgo P, Hohmann J, Kuiate JR, Tane P (2012) Antimicrobial and antioxidant activity of kaempferol rhamnoside derivatives from Bryophyllum pinnatum. BMC Res Notes 5:158

Teiten M-H, Gaascht F, Dicato M, Diederich M (2012) Targeting the Wingless signaling pathway with natural compounds as chemopreventive or chemotherapeutic agents. Curr Pharm Biotechnol 13(1):245-254

Teixeira S, Siquet C, Alves C, Boal I, Marques MP, Borges F, Lima JL, Reis S (2005) Structureproperty studies on the antioxidant activity of flavonoids present in diet. Free Radic Biol Med 39(8):1099-1108

Treutter D (2006) Significance of flavonoids in plant resistance: a review. Environ Chem Lett 4(3):147-157

Tsiklauri L, An G, Ruszaj DM, Alaniya M, Kemertelidze E, Morris ME (2011) Simultaneous determination of the flavonoids robinin and kaempferol in human breast cancer cells by liquid chromatography-tandem mass spectrometry. J Pharm Biomed Anal 55(1):109-113

Van Dijk C, Driessen AJ, Recourt K (2000) The uncoupling efficiency and affinity of flavonoids for vesicles. Biochem Pharmacol 60(11):1593-1600

Venkatesan T, Sorimuthu Pillai S (2012) Antidiabetic activity of gossypin, a pentahydroxyflavone glucoside, in streptozotocin-induced experimental diabetes in rats. J Diabetes 4(1):41-46

Vishnu Prasad CN, Suma Mohan S, Banerji A, Gopalakrishnapillai A (2009) Kaempferitrin inhibits GLUT4 translocation and glucose uptake in 3T3-L1 adipocytes. Biochem Biophys Res Commun 380(1):39-43

Vissiennon C, Nieber K, Kelber O, Butterweck V (2012) Route of administration determines the anxiolytic activity of the flavonols kaempferol, quercetin and myricetin - are they prodrugs? J Nutr Biochem 23(7):733-740

Viswanathan S, Thirugnana Sambantham P, Reddy K, Kameswaran L (1984) Gossypin-induced analgesia in mice. Eur J Pharmacol 98(2):289-291 
Wei Y, Xie Q, Fisher D, Sutherland IA (2011) Separation of patuletin-3-O-glucoside, astragalin, quercetin, kaempferol and isorhamnetin from Flaveria bidentis (L.) Kuntze by elution-pumpout high-performance counter-current chromatography. J Chromatogr A 1218(36):6206-6211

Williams CA, Grayer RJ (2004) Anthocyanins and other flavonoids. Nat Prod Rep 21(4):539-573

Williamson G, Manach C (2005) Bioavailability and bioefficacy of polyphenols in humans. II. Review of 93 intervention studies. Am J Clin Nutr 81(1 Suppl):243S-255S

Wu M-Y, Hung S-K, Fu S-L (2011) Immunosuppressive effects of fisetin in ovalbumin-induced asthma through inhibition of NF- $\mathrm{BB}$ activity. J Agric Food Chem 59(19):10496-10,504

Yang J-G, Liu B-G, Liang G-Z, Ning Z-X (2008) Structure-activity relationship of flavonoids active against lard oil oxidation based on quantum chemical analysis. Molecules 14(1):46-52

Yang W, Sun J, Lu W, Li Y, Shan L, Han W, Zhang WD, Yu B (2010) Synthesis of kaempferol 3-O-(3",6"-di-O-E-p-coumaroyl)-beta-D-glucopyranoside, efficient glycosylation of flavonol 3-OH with glycosyl o-alkynylbenzoates as donors. J Org Chem 75(20):6879-6888

Yang L, Chen Q, Wang F, Zhang G (2011a) Antiosteoporotic compounds from seeds of Cuscuta chinensis. J Ethnopharmacol 135(2):553-560

Yang S, Peng L, Su X, Chen F, Cheng Y, Fan G, Pan S (2011b) Bioassay-guided isolation and identification of antifungal components from propolis against Penicillium italicum. Food Chem 127(1):210-215

Yang Y, Choi JK, Jung CH, Koh HJ, Heo P, Shin JY, Kim S, Park W-S, Shin H-J, Kweon D-H (2011c) SNARE-wedging polyphenols as small molecular botox. Planta Med 78(3):233-236

Yu M-S, Lee J, Lee JM, Kim Y, Chin Y-W, Jee J-G, Keum Y-S, Jeong Y-J (2012) Identification of myricetin and scutellarin as novel chemical inhibitors of the SARS coronavirus helicase, nsP13. Bioorg Med Chem Lett 22:4049-4054

Yun BS, Lee IK, Kim JP, Chung SH, Shim GS, Yoo ID (2000) Lipid peroxidation inhibitory activity of some constituents isolated from the stem bark of Eucalyptus globulus. Arch Pharm Res 23(2):147-150

Zhen L, Zhu J, Zhao X, Huang W, An Y, Li S, Du X, Lin M, Wang Q, Xu Y (2012) The antidepressant-like effect of fisetin involves the serotonergic and noradrenergic system. Behav Brain Res 228(2):359-366 